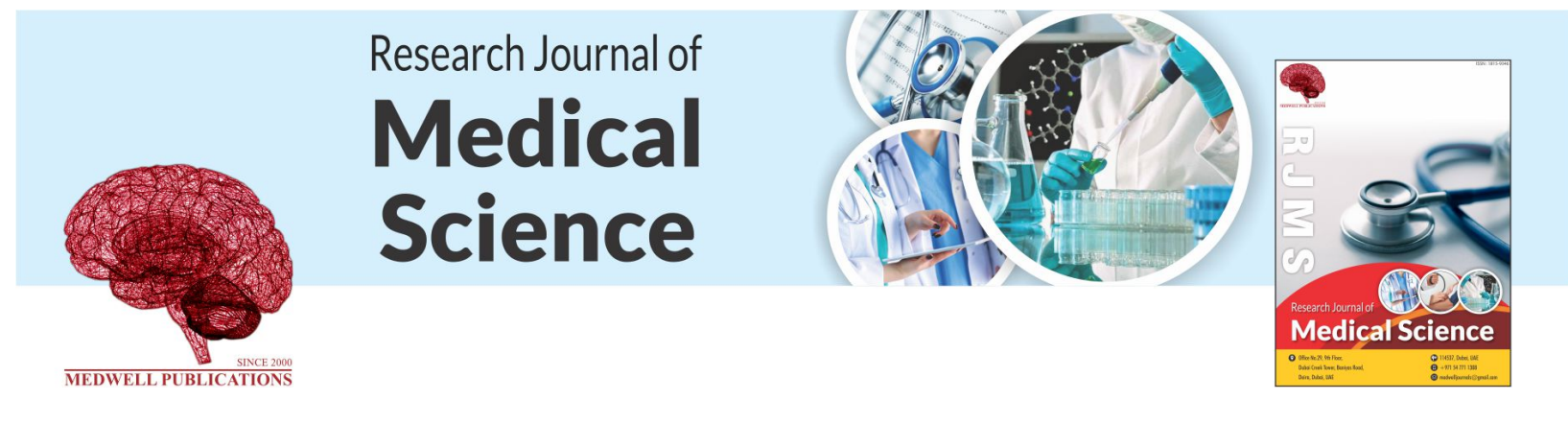

\title{
Nano Silica and Nano Graphene Used in Dental Fillers: The Relation Between the Mechanical and Topography Properties
}

Dhulfiqar Ali Hameed and Nihadabdul Ameer

Department of Physics, College of Sciences, University of Babylon, Babil, Iraq

Key words: Nanographene, nanosilica, surface morphology, compressive strength, roughness, curing

\section{Corresponding Author:}

Dhulfiqar Ali Hameed

Department of Physics, College of Sciences, University of Babylon, Babil, Iraq

Page No.: 20-25

Volume: 14, Issue 1, 2020

ISSN: $1815-9346$

Research Journal of Medical Sciences

Copy Right: Medwell Publications
Abstract: In the modern medicine, there are a lot of medical uses for the nanomaterial's because it has a physical and mechanical features that is suitable with a lot of medical technologies. That we use the nano silica and nano graphene to improvement the mechanical properties of light-curing dental fillings. Nanographene and nanosilica added to composite resin have been blended with resin composite and with precise weight ratios. The fillers formed by LED curing during three time periods 20, 25, 30 sec mold made in dimensions $(6 \times 3 \mathrm{~mm})$. The results of the mechanical properties of the fillings containing of nano graphene (compressive strength test) showed that it is more than the compressive strength of nano silica. The reason for the high compressive strength of fillings containing of nano graphene is due to the roughness of the surface of the fillings nano graphene higher than the roughness of the fillings nano silica surface as shown in the AFM measurement of the atomic force microscope. All the results of the study are within the International Quality Standards (ISO 4049) for dental restoration materials. The increase of the time period of the curing is very important to improve the polymerization process which greatly advances the mechanical and physical properties. The study of mechanical properties has shown that the nano graphene filler to look at compressive strength is more than the compressive strength of nano-silica. The relative roughness of the RMS indicates that the surface of the formed, crystallized and super smooth solids is as indicated in the Atomic Force Microscopy (AFM).

\section{INTRODUCTION}

Significant interest in the fabrication of nano-materials over the last 2 decades has seen the development of nano-balls, tubes, wires, ribbons and sheets in a variety of materials including carbon and silicon. Interestingly, the motivation for fabricating structures of this size arises from their unique physical 
properties which allow them to be used in ways that their bulk counterparts cannot ${ }^{[1]}$. Nano products that have the widest application in routine dental clinical practice are resin-based nanocomposites. Dental Resin-Based Composites (RBC) are tooth-colored restorative materials that consist of organic resin matrix, inorganic filler particles, silane coupling agents and initiators and activators for the photo-polymerization ${ }^{[2]}$.

Formulation of filler particles have been passed from macro-to the nano-particles. The development of nanotechnology has led to a significant improvement in the evolution of dental composites. Due to the relative poor mechanical strength, these materials are indicated for use in low-stress oral regions ${ }^{[3]}$. Trying to create a material that meets both of these properties, the mechanical resistance and the aesthetic and polishing qualities, nanofillers have been developed and nano composites $^{[4]}$.

Dental composites have traditionally been classified according to their filler particle sizes including macrofilled composites, microfilled composites, hybrid composites and recently, nanocomposites with filler sizes below $100 \mathrm{~nm}$. This technology produces a smoother surface with higher translucency and polishability, comparable to those of micro filled composites while their physical properties and wear resistance remain equivalent to those of several hybrid composites. Because the low particle size in the filling and the uniform distribution of particles within it are of high potential to improve the fillings ${ }^{[5]}$. Furthermore, nano particles provide superior polishability and tend to distribute mechanical stress more uniformly than irregularly shaped particles which leads to improved mechanical properties including compressive strength ${ }^{[6]}$. Where compressive strength $(\sigma)$ is the most important feature of dental fillings where the test of compressive strength is important in laboratory analyzes which are usually good indicators to simulate the forces that are exposed to fillings during chewing in the mouth, so, toothpastes must have a high value of compressive strength to withstand the external forces produced by chewing ${ }^{[7]}$.

As well as mechanical properties (compressive strength) are correlated with the surface roughness of the restorative dental. There are varioussystems available today to estimate the surface texture of restorative dental, including Atomic Force Microscopy (AFM) which is the greatest common. This technique was used in the present study because it was quick, simple and reliable for comparative assessment of surface roughness characteristics. Materials with larger filler size are generally showing higher surface roughness than those materials with smaller filler size ${ }^{[8]}$. Although, reported that surface roughness of finished resin-composite materials was not dependent only to the size of filler particle. More recent study confirmed that surface roughness of finished resin-composite materials was dependant to the size, shape and type of filler particles $^{[9]}$.

This article describes a study on the development of a dental nano composite that has the mechanical properties required for restorative dental with improved surface roughness acceptable. the basic roughness parameter such as Ra, RMS is used to describe the surface only through its amplitude. However, in this study, nano particles was mixing with the (Composan LCM). Subsequently, experimental nano composites were prepared with selected monomers ratios and filler contents and the surface morphology, surface roughness and mechanical properties were evaluated in order to prove their applicability and reliability.

\section{MATERIALS AND METHODS}

The nanosilica with thickness range $(3-6 \mathrm{~nm})$, diameter $(10 \mathrm{~nm})$ and nano graphene with thickness range $(6-8 \mathrm{~nm})$, diameter $(15 \mathrm{~nm})$ were has been commercially processed by US Research Nanomaterial's, Sky Spring Nanomaterial's, Inc., respectively. This nanoparticles that was used in this reseach as a base material to which the restorative dental were added and examined is dental restorative filling called "COMPSAN LCM". The degree of shade of this filling is A1; A1 means that this material is the most transparency of all dental restorative filling that are used now in treating tooth; this restorative filling allows most of the radiation intensity to penetrate inside the material. Also, this filling follows the specifications of comprehensive quality system (ISO 4049/2000); this dental filling is not toxic, and it is assumed micro hybrid composite. The company manufacturer is PROMEDICA DOMAGKSTR 24537 NEUMUNSTER and it is made in Germany.

This material consists of a mixture of Bis-Gma in ratio of $10-20 \%$ and UDMA in ratio of $5-10 \%$; the percentage of filler materials from the whole volume is $60 \%$ and from the total weight is $76.5 \%$. Composan LCM consists of the following materials:

- Methacrylate which is the polymer base

- Barium glass which is a filler material

- Salinized which is combination material

- Amorphous silica; it is filler

- Hydrophobia which is water solvent material

Specimen preparation: The weight ratios of nano silica and nano graphene are prepared. In this study, a type of stainless steel mold made by the researchers (Saadi 


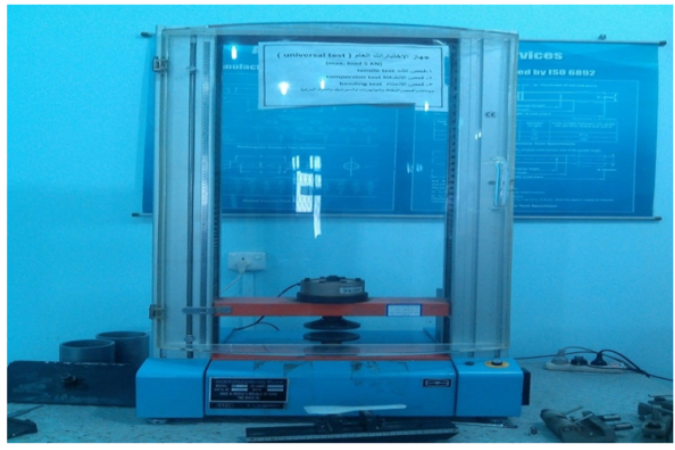

Fig. 1: Compression strength tester

Sharshab Diab and his group $)^{[10]}$ was used. These molds are on a cylindrical cavity of $3 \mathrm{~mm}$ diameter and thickness of $6 \mathrm{~mm}$. Used to prepare suitable samples after mixing (Composan LCM) with nanoparticles, respectively.

After measurement that high compressive strength restorative dental were grinded with a mill and converted to fine powder. A weight ratio $(0.1 \mathrm{~g})$ of both types was dissolved and dissolved in $(2 \mathrm{~mL})$ of ethanol, respectively. We use the ultrasonic device to mix them together decomposition on the substrates of a clean glass slide to prepare thin films on a glass surface to study of Surface Morphology using Atomic Force Microscopy (AFM).

Devices used: The apparatuses used in this project to measure the mechanical properties of dental fillings and surface morphology of the fillings samples are:

Compressive strength test: To measure the compression test, samples of $3 \mathrm{~mm}$ diameter and $6 \mathrm{~mm}$ thickness cylindrical shape were used. This examination was made by "microcomputer controlled electronic universal testing machine "model WDW-56 which has the following data: capacity is $5 \mathrm{KN}$; serial number is 0536 and it is made in China. The place of work is University of Babylon/Materials Engineering College/nonmetallic department. Figure 1 illustrates the device.

Atomic Force Microscope (AFM): This instrument is used to take a look on surfaces on a molecular level. It observes the surface roughness and topography of deposited thin films. This device determines the roughness and root mean square, an Atomic Force Microscope (AFM) are used. The most important part of an atomic force microscope is the tip with its nano scale radius of curvature. The tip is attached to a micron scale cantilever which reacts to the Van der Waals interaction and other forces between the tip and sample as shown in Fig. 2.

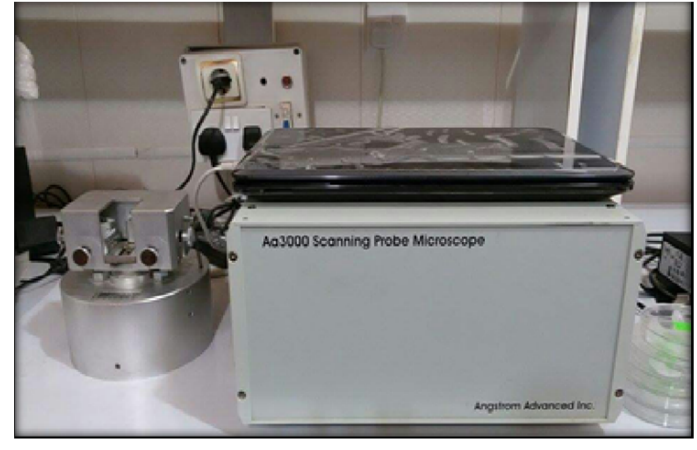

Fig. 2: The system of AFM

\section{RESULTS AND DISCUSSION}

Compression strength for restorative dental: Figure 3 and 4 and Table 1 and 2 shows that the highest compressive strength value for nanosilica fillings was $250 \mathrm{MPa}$ at $0.2 \% \mathrm{~g}$ during the $30 \mathrm{sec}$ period, down to a minimum of $120 \mathrm{MPa}$ at $1 \% \mathrm{~g}$ over the $20 \mathrm{sec}$ while nano graphene, the highest compressive strength $339 \mathrm{MPa}$ at $0.2 \% \mathrm{~g}$ during the $30 \mathrm{sec}$, down to a minimum of $120 \mathrm{MPa}$ at $0.1 \% \mathrm{~g}$ during the $20 \mathrm{sec}$.

It is clear that compressive strength increased with increased exposure time for nano-silica and nano graphene, these nanomaterial's can improve compressive strength of the restorative dental due to high mechanical properties for both.

Therefore, increasing the exposure time increases the number of monomers converted to polymers and enhances the polymerization process thereby increasing the compressive strength value of restorative $\operatorname{dental}^{[11]}$.

Therefore, compressive strength increased with increased exposure time for nano silica and nano graphene. These nanoparticles are effective in enhancing the compressive strength of the compound due to their large mechanical properties.

It is interesting to note that the addition of nano graphene at $(0.02 \%$ g) showed a significant improvement in compressive strength at time $(30 \mathrm{sec})$ more than in the nano silica due to the nano graphene molecules have the strength and durability produced by the structure of the six-crystal as well as random distribution of graphene, there for the bond between graphene sheets is therefore, able to re-link to form and modify links with composites which can lead to hierarchical order arrangement due to existing strong bonding properties such as covalent bonds and coordinate covalent bond. This offers remarkable mechanical reinforcements to form the best structure for restorative $\operatorname{dental}^{[12]}$. 
Res. J. Med. Sci., 14 (1): 20-25, 2020

Table 1: Effect of nano-silica addition to resin composites on compressive strength (MPa) during time periods 20,25, 30 sec

\begin{tabular}{lccccc}
\hline Light period $(\mathrm{sec})$ & $\sigma(\mathrm{MPa})$ at $0.02 \% \mathrm{~g}$ & $\sigma(\mathrm{MPa})$ at $0.05 \% \mathrm{~g}$ & $\sigma(\mathrm{MPa})$ at $0.1 \% \mathrm{~g}$ & $\sigma(\mathrm{MPa})$ at $0.2 \% \mathrm{~g}$ & $\sigma(\mathrm{MPa})$ at $1 \% \mathrm{~g}$ \\
\hline 20 & 160 & 133 & 132 & 130 & 120 \\
25 & 190 & 145 & 144 & 138 & 133 \\
30 & 250 & 160 & 146 & 142 & 135 \\
\hline
\end{tabular}

Table 2: Effect of nano graphene addition to resin composites on compressive strength (MPa) during time periods 20, 25, $30 \mathrm{sec}$

\begin{tabular}{lccccc}
\hline Light period $(\mathrm{sec})$ & $\sigma(\mathrm{MPa})$ at $0.02 \% \mathrm{~g}$ & $\sigma(\mathrm{MPa})$ at $0.05 \% \mathrm{~g}$ & $\sigma(\mathrm{MPa})$ at $0.07 \% \mathrm{~g}$ & $\sigma(\mathrm{MPa})$ at $0.09 \% \mathrm{~g}$ & $\sigma(\mathrm{MPa})$ at $0.1 \% \mathrm{~g}$ \\
\hline 20 & 162 & 148 & 143 & 133 & 121 \\
25 & 299 & 270 & 161 & 145 & 133 \\
30 & 339 & 330 & 170 & 166 & 139 \\
\hline
\end{tabular}

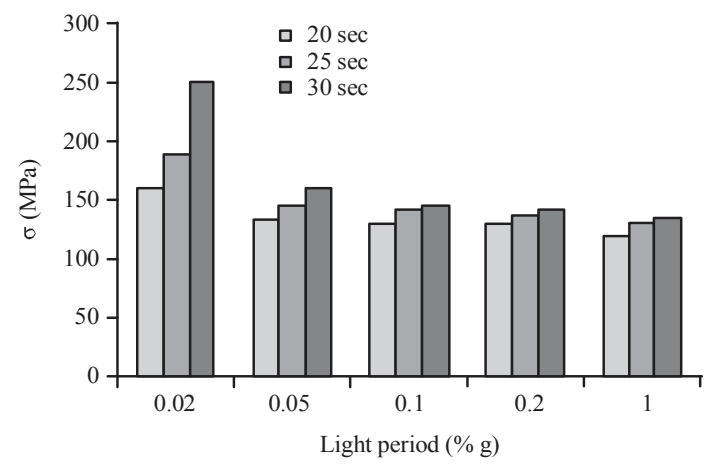

Fig. 3: Effect of nano-silica addition to resin composites on compressive strength $(\mathrm{MPa})$ during time periods $(20,25,30 \mathrm{sec})$

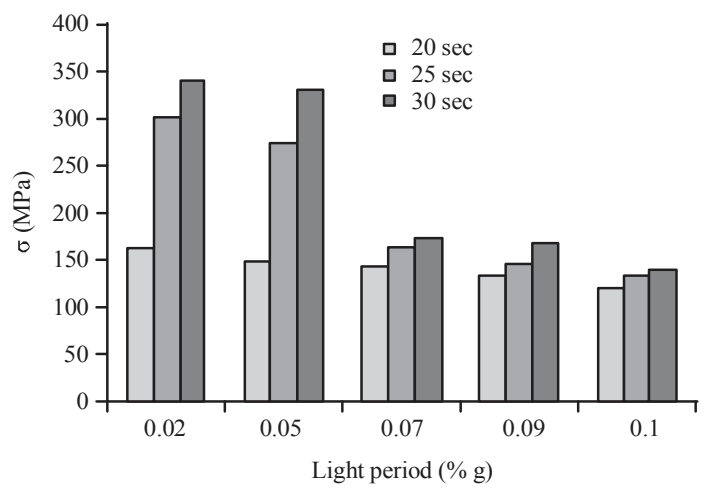

Fig. 4: Effect of nano-graphene addition to resin composites on compressive strength $(\mathrm{MPa})$ during time periods $(20,25,30 \mathrm{sec})$

Also of the above forms, when ratios of the nanomaterial's increase, the compressive strength of the restorative dental are lower ${ }^{[13]}$. This can be explained by the fact that high ratios of nanomaterial's will increase the viscosity of the phase resin and therefore, in the restorative dental that contain a fraction of the nanomaterial's. The more viscous resins will due to in inconsistent association in the resin composites, as resulting in reduced compressive strength, the amount of nanomaterial's added has a threshold down which the compressive strength is reduced ${ }^{[14,15]}$.
Atomic Force Microscopy (AFM) for restorative dental: Surface morphology was studied using Atomic Force Microscope (AFM) images that produce topographic images of the surface of restorative dental thin films with very high amplification. Surface roughness is important in the description of restorative dental, since, surface composition and formation of dental compounds affect bacterial adhesion and accumulate on the surface of the raw material more than black in dental ${ }^{[16]}$. As well as the morphology of fillings has a significant impact on filling properties which have proved to be critical influences in their mechanical properties (compressive strength) ${ }^{[17]}$.

The roughness parameters depend on several features such as the size of the nanomaterial's, the ratios of the surface area occupy, hardness, the polymer rate conversion and the filler reaction ${ }^{[18]}$. The material in size nano add in the restorative dentals has shown that improve the roughness of the fillings for it can have a more homogeneous dispersion in the polymer matrix ${ }^{[6]}$.

The qualitative analysis of AFM images for both types of restorative dentals, as shown in Table 3 and Fig. 5, shows that the surface roughness of the restorative dentals containing nano graphene $(40.8 \mathrm{~nm})$ is greater than the dental fillings. This nanotechnology is directly related to the size, diameter, thickness and relative capacity of the material on the volumetric load. This leaves areas with soft. Easy, low-grade resin and thus, reduces the surface roughness of the restorative dentals ${ }^{[19,2]}$. So, the roughness restorative dentals of the nano graphene are made from the thickness, diameter and size of the nano graphene which is larger than the nano-silica. The coefficient of roughness with increasing diameter, area and thickness of nanomaterial's resulted in a linear relationship where the size and shape of nanomaterial's had a significant impact on surface roughness coefficients of this series of composites ${ }^{[8]}$. The presence of nanomaterial's in the resin composites either results in the emergence or removal of the fill from the surface layer and the remaining distortions and defects in the surface.

Although, the values of roughness were different, the values were still lower than $200 \mathrm{~nm}$ reported as the initial point of accumulation of bacterial plaque and the risk of licorice and gingivitis ${ }^{[6]}$. 
Res. J. Med. Sci., 14 (1): 20-25, 2020
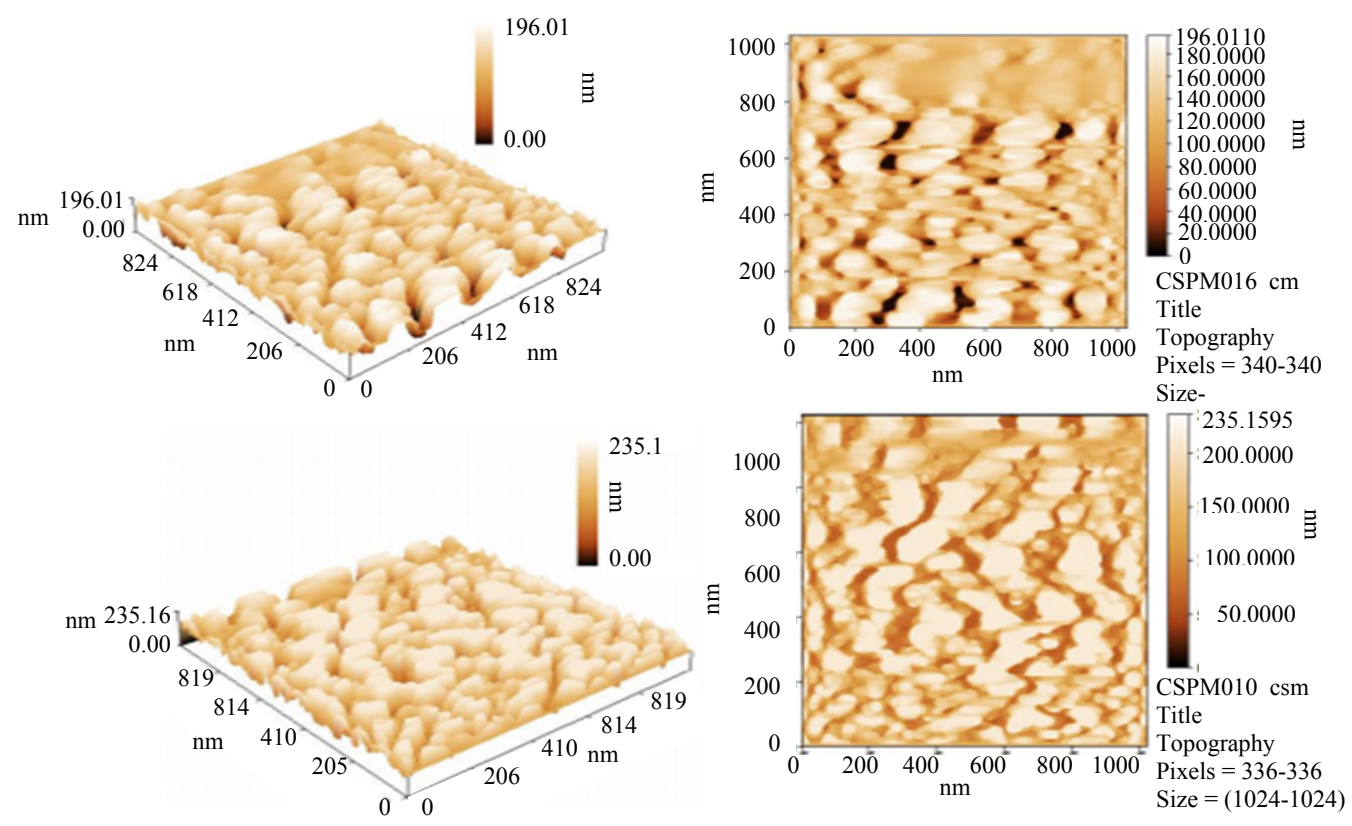

Fig. 5(a-b): AFM images of surface roughness of the resin composites in 3D, 2D, (a) After the addition of nano silica and (b) After the addition of nano graphenes

Table 3: Surface roughness factors for the resin composites after addition of nano-silica and addition of nano-graphene

\begin{tabular}{lcc}
\hline Samples & Average roughness $(\mathrm{nm})$ & RMS $(\mathrm{nm})$ \\
\hline Filler of nano silica & 29.5 & 38.7 \\
Filler of nano graphene & 40.8 & 47.5 \\
\hline
\end{tabular}

\section{CONCLUSION}

All the results of the study are within the International quality Standards (ISO 4049) for dental restoration materials. The increase of the time period of the curing is very important to improve the polymerization process which greatly advances the mechanical and physical properties. Reducing the ratio of nanoparticles added to the resin composites develops mechanical and physical properties better than high ratios. The study of mechanical properties has shown that the nano graphene filler to examine compressive strength is more than the compressive resistance of nano-silica. The reason for the compressive resistance of high nano graphene is due to the roughness of the surface of the nano graphene higher than the silica surface roughness as shown in the AFM measurement. The relative roughness of the RMS indicates that the surface of the formed, crystallized and super smooth solids is as indicated in the Atomic Force Microscopy (AFM).

\section{REFERENCES}

01. Spizzirri, P.G., J.H. Fang, S. Rubanov, E. Gauja and S. Prawer, 2010. Nano-Raman spectroscopy of silicon surfaces. Mater. Forum, Vol. 34,
02. Lainovic, T., M. Vilotic, L. Blazic, D. Kakas, D. Markovic and A. Ivanisevic, 2013. Determination of surface roughness and topography of dental resin-based nanocomposites using AFM analysis. Bosnian J. Basic Med. Sci., 13: 34-43.

03. Sideridou, I.D., M.M. Karabela and E.C. Vouvoudi, 2011. Physical properties of current dental nanohybrid and nanofill light-cured resin composites. Dent. Mater., 27: 598-607.

04. Mitra, S.B., D. Wu and B.N. Holmes, 2003. An application of nanotechnology in advanced dental materials. J. Am. Dent. Assoc., 134: 1382-1390.

05. Hasnain, M.S. and A.K. Nayak, 2019. Nanocomposites for Improved Orthopedic and Bone Tissue Engineering Applications. In: Applications of Nanocomposite Materials in Orthopedics, Inamuddin, A.M. Asiri and A. Mohammad (Eds.)., Woodhead Publishing, Sawston, UK., pp: 145-177.

06. Rahim, T.N.A.T., D. Mohamad, A.R. Ismail and H.M. Akil, 2011. Synthesis of Nanosilica Fillers for Experimental Dental Nanocomposites and Their Characterisations. J. Phys. Sci., 22: 93-105.

07. Suhani, M.F., G. Baciut, M. Baciut, R. Suhani and S. Bran, 2018. Current perspectives regarding the application and incorporation of silver nanoparticles into dental biomaterials. Clujul Med., 91: 274-279.

08. Senawongse, P. and P. Pongprueksa, 2007. Surface roughness of nanofill and nanohybrid resin composites after polishing and brushing. J. Esthetic Restor. Dent., 19: 265-273. 
09. Marghalani, H.Y., 2010. Effect of finishing/polishing systems on the surface roughness of novel posterior composites. J. Esthetic Restor. Dent., 22: 127-138.

10. Sadat-Shojai, M., M. Atai, A. Nodehi and L.N. Khanlar, 2010. Hydroxyapatite nanorods as novel fillers for improving the properties of dental adhesives: Synthesis and application. Dental Mater., 26: 471-482.

11. Banava, S. and S. Salehyar, 2008. In vitro comparative study of compressive strength of different types of composite resins in different periods of time. Iran. J. Pharm. Sci., 4: 69-74.

12. Ge, Z., L. Yang, F. Xiao, Y. Wu, T. Yu, J. Chen and Y. Zhang, 2018. Graphene family nanomaterials: Properties and potential applications in dentistry. Intl. J. Biomater., 2018: 1-12.

13. Malik, S., F.M. Ruddock, A.H. Dowling, K. Byrne, W. Schmitt, I. Khalakhan and J.P. Hill, 2018. Graphene composites with dental and biomedical applicability. Beilstein J. Nanotechnol., 9: 801-808.

14. Rezvani, M.B., M. Atai, F. Hamze and R. Hajrezai, 2016. The effect of silica nanoparticles on the mechanical properties of fiber-reinforced composite resins. J. Dent. Res. Dent. Clinics Dent. Prospects, 10: $112-117$.
15. Lee, J.H., C.M. Um and I.B. Lee, 2006. Rheological properties of resin composites according to variations in monomer and filler composition. Dent. Mater., 22: 515-526.

16. Shah, P.K. and J.W. Stansbury, 2014. Role of filler and functional group conversion in the evolution of properties in polymeric dental restoratives. Dent. Mater., 30: 586-593.

17. Rashid, H., 2014. The effect of surface roughness on ceramics used in dentistry: A review of literature. Eur. J. Dent., 8: 571-579.

18. Basim, G.B., 2018. Properties of materials EMA 6001 section: 34H3. Rhines Hall, Gainesville, Florida. https://mse.ufl.edu/wp-content/uploads/ GBB_Syllabus-EMA-6001.pdf

19. Kimyai, S., S. Savadi-Oskoee, A.A. Ajami, A. Sadr and S. Asdagh, 2011. Effect of three prophylaxis methods on surface roughness of giomer. Med. Oral. Patologia Oraly Cirugia Bucal, 16: e110-e114. 